\title{
OS REFLEXOS DA FORMAÇÃO CONTINUADA EM SERVIÇO POR MEIO DO PROGRAMA PROFUNCIONÁRIO: A PERCEPÇÃO DOS CURSISTAS
}

\author{
THE REFLEXES OF ONGOING FORMATION IN SERVICE THROUGH THE PRO- \\ EMPLOYEE PROGRAM: THE PERCEPTION OF CURSORS
}

DOI: http://dx.doi.org/10.23926/RPD.2526-2149.2019.v4.n1.p334-354.id405

\author{
Nair Mendes de \\ Oliveira \\ Mestranda em Ensino \\ (UNIC) \\ Pedagoga no Instituto \\ Federal de Mato Grosso \\ (PROEN/IFMT) \\ nmoliveira.5@gmail.com
}

\section{Maria Geni Pereira \\ Bilio}

Mestranda em Ensino

(UNIC)

Professora de I a IV da Rede

Municipal de Várzea

Grande-MT

genibilioprofessora@gmail.c

$\underline{\text { om }}$

\section{Enerci Candido \\ Gomes}

Mestre m Ensino (UNIC)

Professora da Rede Estadual

de Educação de Mato Grosso

(SEDUC/MT)

candidoenerci@yahoo.com.b

$\underline{\mathrm{r}}$

\section{Maria das Graças \\ Campos}

Doutora em Políticas

Públicas e Formação

Humana (UERJ)

Professora da Universidade

de Cuiabá (UNIC)

mdgcampos@uol.com.br
Resumo: Este estudo tem por objetivo analisar os reflexos da prática docente desenvolvida na formação continuada em serviço por meio do Programa Profuncionário, junto aos cursistas do Polo Cefapro Diamantino, no município de Nova Maringá - MT, cuja finalidade consiste na formação dos trabalhadores não docentes que atuam na escola. A experiência possibilita a ressignificação da razão de ser servidor, atribuindo-lhes o sentimento de pertença e de educador. Para atender aos objetivos propostos por esta investigação, elegemos a pesquisa qualitativa para a qual utilizamos fontes, dentre as quais, bibliográfica, documental e estudo de caso, tendo como abordagem a coleta de dados, observação e diálogo com os participantes via entrevista semiestruturada. Os resultados evidenciam que os servidores visualizam no Programa a oportunidade de crescimento pessoal e profissional. Mesmo diante de algumas dificuldades os alunos têm buscado meios para ampliar o uso das Tecnologias de Informação e do Conhecimento, na busca por realização e melhores resultados do trabalho. Os cursistas se esforçam para realizar com responsabilidade todas as atividades propostas para melhorar a qualidade da função que lhes é atribuída, bem como para desenvolver uma prática educativa significativa na instituição de ensino em que estão inseridos.

Palavras Chave: Reflexos da formação continuada. Percepção. Ressignificação da prática educativa não docente.

\begin{abstract}
This study has the objective of analyzing the reflexes of the teaching practice developed in the continuing training in service through the Profuncionário Program, together with the Cefapro Diamantino Polo students, in the municipality of Nova Maringá - MT, whose purpose is to provide training for non - teachers who work in school. The experience makes possible the resignification of the reason for being a server, attributing to them the feeling of belonging and the educator. In order to meet the objectives proposed for this research, we chose the qualitative research for which we use sources, among which, bibliographical, documentary and case study, taking as an approach data collection, observation and dialogue with the participants through a semi-structured interview. The results show that the servers visualize in the Program the opportunity of personal and professional growth. Even in the face of some difficulties, students have sought ways to increase the use of Information Technology and Knowledge in the search for achievement and better results of work. The trainees strive to carry out with responsibility all activities proposed to improve the quality of the role assigned to them, as well as to develop a meaningful educational practice in the institution of education in which they are inserted.
\end{abstract}

Keywords: Reflections on continuing education. Perception. Resignification of non-teaching educational practice. 


\section{INTRODUÇÃO}

$\mathrm{Na}$ perspectiva de uma Política Pública inclusiva de educação, o Programa Profuncionário no estado de Mato Grosso consiste na possibilidade de formação continuada em serviço voltada para os servidores da educação básica pública que praticam atividades educativas, contudo não docentes no interior da escola, dentre os quais podemos elencar os vigias, porteiros, merendeiras, serviços gerais e apoio administrativo. Trata-se de um programa em que é ofertado curso técnico subsequente ao nível médio.

Conforme o Ministério da Educação e Cultura- MEC:

O Profuncionário é o Programa Indutor de Formação Profissional em Serviço dos Funcionários da Educação Básica Pública, em habilitação compatível com sua atividade educativa, na modalidade da Educação a Distância (EAD). Obedece ao disposto no art. 61 da Lei de Diretrizes e Bases n. 9394/1996, conforme a Lei n. 12.014/2009 e ao disposto no parágrafo único do art. 62-A da Lei de Diretrizes e Bases, por meio do qual a profissionalização tornou-se direito de todos os funcionários da educação. (BRASIL, 2014).

Em conformidade com o pensamento de Bessa (2016, p. 202), o Programa Profuncionário “[...] é o único programa de formação profissional, no Brasil, hoje, como política indutiva do Governo Federal, ofertado nacionalmente”. Nesta direção, o Programa cumpre com as prerrogativas jurídico-políticas, em especial com as premissas recomendadas pela LDB e dos Pareceres e Resoluções do CNE (BRASIL, 2014b).

Para João Monlevade (2009), os cursos de Alimentação Escolar, Infraestrutura Escolar, Multimeios Didáticos e Secretaria Escolar, do profuncionário, vão além da formação técnica:

[...] não se trata somente de multiplicar as habilidades da merendeira, de inserir o pessoal da limpeza no mundo da higiene química, de informatizar as ações dos auxiliares de secretaria e de biblioteca, de modernizar os aparatos de segurança. Para terem identidade de educadoras e educadores, os técnicos e os tecnólogos em multimeios didáticos, em alimentação, em infraestrutura e em gestão escolar precisam assumir o compromisso com o projeto político pedagógico da escola e com a gestão democrática do sistema de ensino, engajar-se na formação continuada, no trabalho cotidiano de planejamento e avaliação coletiva do espaço e do tempo escolares (MONLEVADE, 2009, p. 350).

Tendo em vista a diversidade dos atores sociais não docentes que atuam no dia a dia da vida escolar, os cursos que fazem parte do Programa Profuncionário, estão distribuídos em quatro dimensões: Alimentação Escolar, Multimeios Didáticos, Secretaria Escolar, Infraestrutura Escolar e, em conformidade com o Catálogo Nacional de Cursos Técnicos fazem parte do Eixo Tecnológico de Desenvolvimento Educacional e Social, pertencentes à Agenda 21 da Formação Técnica Profissional. Importante destacar que a legislação e a normatização específicas para a formação profissional de funcionários da educação, no Brasil ainda são 
recentes e se encontram prescritas no contexto dos princípios orientadores da educação profissional em geral (BRASIL, 2014b).

Ainda que muito recentemente, em um contexto histórico, o processo formativo nesta perspectiva iniciou mediante desenvolvimento de uma experiência piloto no ano de 2005 desencadeada pelos estados de Mato Grosso do Sul, Pernambuco, Paraná, Piauí e Tocantins, cujo objetivo consistia em construir e reconstruir a identidade profissional dos funcionários da educação, sendo no ano de 2006 expandido para mais doze estados brasileiros.

\section{Referencial TeóRICo}

O Programa Profuncionário se configura como uma Política Pública nacional de formação originada no governo popular no Brasil em 2011. Contudo, em um curto espaço de tempo sofreu alterações no que se refere à gestão, evidenciada na Portaria Normativa do MEC $\mathrm{n}^{\mathrm{o}}$ 1.547/2011, em que a responsabilidade do Programa, antes da Secretaria de Educação Básica (SEB) passa a ser da Secretaria de Educação Profissional e Tecnológica (SETEC), entrando em cena os Institutos Federais de Educação, Ciência e Tecnologia. Tendo em vista a especificidade do curso na modalidade à distância, o Programa passou a fazer parte da Rede de Educação Técnica a Distância (Rede e-Tec). A partir de então, seu desenvolvimento é orquestrado pelos Institutos Federais (ARRIAL, 2016).

O IFMT realizou a oferta da primeira edição do Programa Profuncionário no ano de 2013 em parceria com a Secretaria de Estado de Educação de Mato Grosso- SEDUC/Cefapro, formando 15 polos em todo o Estado: Alta Floresta, Barra do Garças, Cáceres, Confresa, Cuiabá, Diamantino, Juara, Juína, Matupá, Pontes e Lacerda, Primavera do Leste, Rondonópolis, São Félix do Araguaia, Sinop e Tangará da Serra.

A segunda edição do Programa Profuncionário ofertada pelo IFMT ocorreu no ano de 2015 também em parceria com a da Secretaria de Estado de Educação de Mato GrossoSEDUC. Este artigo utiliza os dados da terceira edição do Programa Profuncionário desenvolvido pelo IFMT, cujo início se deu no ano de 2017, alunos matriculados nos cursos de Alimentação Escolar, Multimeios Didáticos, Infraestrutura Escolar e Secretaria Escolar.

O quadro abaixo apresenta o total de vagas ofertadas pelo IFMT, no Programa Profuncionário, no qual se observa um decréscimo do total de vagas ofertadas a partir do curso de Alimentação Escolar. Nos anos de 2013 foram ofertadas 1.350, sendo em 2015, 650 e em 2017 apenas 177 vagas. Situação semelhante ocorreu para os cursos de Infra Estrutura Escolar, Secretaria Escolar. Nota-se ainda que, embora houvesse um acréscimo da oferta de vagas no 
curso de Multimeios Didáticos quando em 2013 foram ofertadas 100 vagas e estas foram ampliadas em 150 para o ano de 2015. Já em 2017 há um decréscimo para 52 vagas.

Quadro 1 - Oferta de vagas nos anos de 2013, 2015 e 2017

\begin{tabular}{|l|c|c|c|}
\hline \multirow{2}{*}{\multicolumn{1}{c}{ Cursos }} & $\mathbf{2 0 1 3}$ & $\mathbf{2 0 1 5}$ & $\mathbf{2 0 1 7}$ \\
\cline { 2 - 4 } & Vagas Ofertadas & Vagas Ofertadas & Vagas Ofertadas \\
\hline Alimentação Escolar & 1.350 & 650 & 177 \\
\hline Infraestrutura Escolar & 3.944 & 1.250 & 898 \\
\hline Multimeios Didáticos & 100 & 150 & 52 \\
\hline Secretaria Escolar & 1.300 & 450 & 162 \\
\hline Total & $\mathbf{6 . 6 9 4}$ & $\mathbf{2 . 5 0 0}$ & $\mathbf{1 . 2 8 9}$ \\
\hline
\end{tabular}

Fonte: Q-acadêmico/IFMT (07/02/2019).

A distribuição das vagas nos cursos de Alimentação Escolar, Multimeios Didáticos, Infraestrutura Escolar e Secretaria Escolar, é realizada de acordo com a demanda e valores liberados pelo MEC. Na prática, a oferta acontece em conformidade com as vagas oferecidas para as funções de técnicos em alimentação escolar, infraestrutura escolar multimeios didáticos e secretaria escolar em concursos públicos nas diferentes redes de ensino.

Após o resultado, o IFMT responsável pelo desenvolvimento do Profuncionário no Estado de Mato Grosso, encaminha ao Ministério da Educação - MEC, o Plano de Trabalho Anual - PTA, para liberação das verbas que irão custear o desenvolvimento do programa.

\subsection{Organização Pedagógica do Programa Profuncionário}

A referência para a organização pedagógica do Programa Profuncionário considera as orientações legais prescritas no Caderno de Orientações Gerais do Profuncionário (BRASIL, 2014b), a fim de formar e desenvolver uma prática pedagógica coerente com os objetivos da formação continuada de servidores não docentes. Em se tratando da realidade no estado de Mato Grosso, o IFMT é responsável pela oferta e desenvolvimento do Programa, na condição de autarquia federal, possui autonomia para organizar os cursos pedagogicamente conforme sua realidade.

Os Projetos Pedagógicos dos Cursos (PPC), pertencentes ao Programa Profuncionário são elaborados em consonância com o Projeto Pedagógico Institucional (PPI) e a Organização Didática do IFMT cuja finalidade consiste em organizar o conjunto de ações a ser desenvolvido em cada curso (GIL, 2015).

Importante destacar que a proposição explicitada nos PPC`s dos cursos do Programa Profuncionário ofertados pelo IFMT, como fundamental para a proposta político-pedagógica do Programa, em conformidade com o Caderno de Orientações Gerais (BRASIL, 2014b). Diante do exposto, três particularidades distinguem a organização pedagógica dos cursos 
pertencentes ao Programa Profuncionário, a saber: a oferta é realizada a distância com instantes presenciais; a matriz curricular é modular e não unicamente disciplinar, e os componentes curriculares são elaborados considerando núcleos de formação que se cruzam (Ibidem).

Por se tratar de uma oferta vinculada à modalidade de Educação a Distância $(\mathrm{EaD}), \mathrm{o}$ Programa Profuncionário atende a legislação específica relativa a esta modalidade de ensino. Nesta direção, as Diretrizes Curriculares Nacionais para a Educação Profissional Técnica de Nível Médio (Resolução CNE/CEB no 6/2012), ao mencionarem a modalidade EaD, determinam que:

Art. 33 Os cursos técnicos de nível médio oferecidos, na modalidade de Educação a Distância, no âmbito da área profissional da Saúde, devem cumprir, no mínimo, 50\% (cinquenta por cento) de carga horária presencial, sendo que, no caso dos demais eixos tecnológicos serão exigidos um mínimo de $\mathbf{2 0 \%}$ (vinte por cento) de carga horária presencial, nos termos das normas específicas definidas em cada sistema de ensino.

$\S 1^{\circ}$ Em polo presencial ou em estruturas de laboratórios móveis devem estar previstas atividades práticas de acordo com o perfil profissional proposto, sem prejuízo da formação exigida nos cursos presenciais (BRASIL, 2012a, texto digital, grifos meus).

Em se tratando da organização modular do Programa Profuncionário, Bessa (2009, p. 485) menciona que "os módulos foram escritos visando ao objetivo geral de possibilitar que os cursistas possam (des) construir sua identidade profissional: de funcionários de apoio escolar a profissionais, educadores, gestores e cidadãos". Neste sentido, o autor, destaca que os módulos específicos para cada curso desenvolvem temas relativos à realidade escolar, na perspectiva de tema transversal. Cada módulo foca questões específicas, teórico-práticas, possibilitando a compreensão em sua totalidade, mediante diferentes olhares.

Aspecto também pertencente à organização pedagógica do Programa Profuncionário, o cruzamento dos núcleos de formação se dá conforme as Orientações Gerais (BRASIL, 2014b), com especial atenção, em função dos princípios filosóficos, políticos e pedagógicos que sustentam sua proposta político-pedagógica. Tais princípios “[...] são filosóficos porque expressam conceitualmente o sentido da proposta. São políticos porque expressam escolhas feitas entre alternativas possíveis. Por fim, são pedagógicos porque expressam intenção e planejamento educativos" (BRASIL, 2014b, p. 71).

Diante do exposto, em conformidade com o documento orientador (BRASIL, 2014b), os princípios que embasam a proposta pedagógica consistem na indissociabilidade entre teoria e prática; construção de competências e conhecimentos via problematização, investigação e reflexão na vivência prática; e transversalidade temática. Por meio desses princípios, o Programa Profuncionário tem por objetivo afiançar que alguns temas, procedimentos e atitudes 
dialoguem entre os diferentes núcleos, tendo por foco as competências dos sujeitos em formação.

No que tange às competências, as Orientações Gerais (BRASIL, 2014b) enfatizam a competência de "transformar o saber fazer da vivência em prática educativa para a construção de outras relações sociais, mais humanizadas" (Ibidem, p. 79). Assim, mediante destaque para essa competência, é importante considerar a trajetória de cada funcionário estudante, a fim de que as vivências e experiências dos funcionários da escola sejam consideradas durante o processo formativo, por serem sujeitos que possuem um saber adquirido na vivência do fazer cotidiano, nas diferentes escolas em que atuam.

A fim de confirmar a condição dos funcionários de escola enquanto sujeitos da formação e em formação (BRASIL, 2014b), Charlot (2000, p. 33) afirma que o sujeito "age no e sobre o mundo; encontra a questão do saber como necessidade de aprender e como presença no mundo de objetos, de pessoas e de lugares portadores de saber; se produz ele mesmo, e é produzido, através da educação". Nesta direção, cada funcionário experencia possibilidades que vão desenhando o seu fazer diário nas escolas e neste contexto, formando sua identidade.

Neste sentido, o documento orientador (BRASIL, 2014b) destaca que tais aspectos vivenciais e do saber fazer dos funcionários de escola, fornecem a eles uma identidade atual e, às vezes, requer que sejam desconstruídas e reconstruídas para que uma nova identidade profissional seja construída.

Ainda em relação aos princípios listados no documento orientador do Programa (BRASIL, 2014b), a indissociabilidade na relação teoria e prática é defendida tendo em vista que pela teoria é possível abarcar a prática e, simultaneamente, reconstruir essa prática de forma crítica. Assim, "[...] não se aprende teoria para aplicar e usar na prática, mas se aprende e se constrói teoria transformando o saber fazer da vivência cotidiana em prática intencional" (BRASIL, 2014b, p. 72).

Os pressupostos que embasam o desenvolvimento da prática pedagógica que perpassa o Programa Profuncionário vêm ao encontro das ideias de Paulo Freire que foi um dos pioneiros a evidenciar a intencionalidade da prática educativa. Para ele o ato educativo é essencialmente político. Freire (1996) destaca que toda prática educativa requer a presença de sujeitos: um que, ao ensinar, aprende, e outro que, ao aprender, ensina, ressaltando o seu cunho gnosiológico. Assim, a prática educativa, na perspectiva freiriana, inclui o uso de métodos, de técnicas, de materiais e demandam, pelo seu caráter diretivo, objetivos, sonhos, utopias, ideais, perpassados por objetos, conteúdos a serem ensinados e aprendidos. 
Para Freire (1996), do conjunto que compõe a prática educativa, a “[...] qualidade que tem a prática educativa de ser política, de não poder ser neutra". (p.78). Tendo em vista que o Programa Profuncionário tem por preocupação a formação de educadores, a prática dos funcionários de escola pode ser compreendida na perspectiva freiriana, como um ato educativo e político.

Em continuidade aos princípios contidos nas Orientações Gerais do Programa Profuncionário (BRASIL, 2014b) temos a construção de competências e conhecimentos via problematização, investigação e reflexão na vivência e na prática, e transversalidade temática. Contudo, para desenvolver esses princípios, o documento orientador chama a atenção para a necessidade de compreender a partir de que perspectiva o Programa avalia competência, já que, o perfil profissional do egresso dos cursos do Programa Profuncionário é determinado pelas competências que o funcionário estudante deverá adquirir e/ou construir durante o curso. Zabala e Arnau (2010) argumentam que em geral uma proposta de formação profissional se estrutura em torno de competências.

Na perspectiva do documento orientador (BRASIL, 2014b, p. 71) " [...] a competência de um profissional é vista pelo uso que ele faz de valores, conhecimentos e habilidades adquiridos na formação para lidar com uma demanda de trabalho na sociedade". Com base nesta compreensão, na visão de Zabala e Arnau (2010), competência é a capacidade ou a habilidade, para desenvolver tarefas ou mesmo agir diante das situações de maneira eficaz em um determinado contexto. Assim, Zabala e Arnau (2010), defendem ser necessário que sejam mobilizados, ao mesmo tempo de forma inter-relacionada, conhecimentos, atitudes e habilidades.

As Orientações Gerais (BRASIL, 2014b) e Zabala e Arnau (2010) em concordância afirmam que não é satisfatória, para ser competente, dominar certas técnicas e a sua funcionalidade. Ao contrário, faz-se necessário ser útil para o sujeito aquilo que se aprende. No contexto do funcionário de escola, significa poder agir de maneira eficiente e determinada diante de uma situação real.

Nessa direção,

[...] a aquisição de competência não se reduz ao mero saber técnico, como, por exemplo, instalar e desinstalar um computador. Essa atividade está relacionada a fins educativos que envolvem aspectos políticos, éticos, estéticos e científicos, relativos à compreensão do sentido do uso pedagógico/educativo do computador na escola (BRASIL, 2014b, p. 72). 
Em continuidade às prescrições, o documento menciona que os demais princípios, no sentido da construção de competências e conhecimentos via problematização, investigação e reflexão na vivência e na prática e transversalidade temática, possui defesa na compreensão de que os conhecimentos deverão ser reconstruídos pelos funcionários estudantes a partir das suas necessidades situacionais, isto é, nos projetos pedagógicos das escolas e dos órgãos em que trabalham. Tais conhecimentos se referem às prescrições contidas nos estudos no Programa Profuncionário (BRASIL, 2014b).

Assim, no Programa Profuncionário as competências listadas para a formação do perfil profissional de cada uma das habilitações requerem conhecimentos relativos à escola, o que exige a problematização dela e a reflexão quanto sua função social e papel na comunidade, seu trabalho educativo, sobre a produção de cultura e identidade, o projeto político-pedagógico, entre outros elementos. Desta forma, ao estudar a escola, os temas são perpassados uns pelos outros e exigem conhecimentos técnico-científicos que possam subsidiar a compreensão (BRASIL, 2014b).

Por meio da explicação pertinente aos princípios filosóficos, políticos e pedagógicos que apoiam a proposta político-pedagógica do Programa Profuncionário, evidenciamos o terceiro e último aspecto que caracteriza a sua organização, o cruzamento dos núcleos de formação. Tendo em vista os princípios, é possível que alguns temas, procedimentos e atitudes se movam de um núcleo para outro em função das competências dos funcionários estudantes (BRASIL, 2014b).

Assim, os núcleos de formação adotam um caráter flexível em que não mais é conferida maior importância para um em detrimento de outro. Partindo do documento orientador relativo ao Programa Profuncionário (BRASIL, 2014b), mediante contato com diferentes saberes, o saber fazer da vivência, poderá ser problematizado, compreendido, ressignificado, reconstruído via práticas de trabalho na escola, visto que se trata de funcionários estudantes.

Diante do exposto, fazem parte dos núcleos de formação dos cursos do Programa Profuncionário, em conformidade com a Figura 1, a Formação Pedagógica, a Formação Técnica Geral e Específica e a Prática Profissional Supervisionada. Conforme o Caderno de Orientações (BRASIL, 2014b, p. 82), a “grande e original contribuição que o Profuncionário consolidou na história da profissionalização desses trabalhadores da educação foi o caráter técnicopedagógico de sua formação". 
Figura 1 - Cruzamento dos núcleos de formação

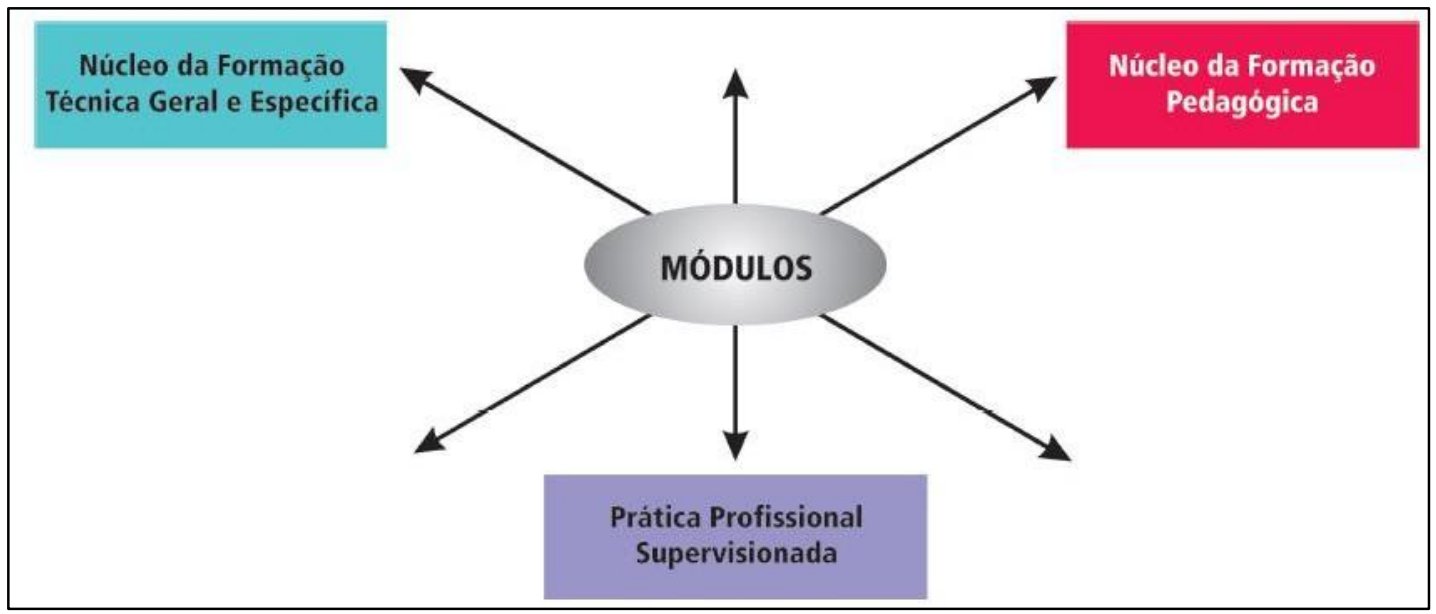

Fonte: Caderno de Orientações Gerais (BRASIL, 2014b, p. 79).

Fica perceptível que na prática os três núcleos de formação se articulam em módulos, de maneira em que os conhecimentos e competências possam ser adquiridos, construídos e experimentados via problematização teórico-prática de assuntos e situações pertencentes aos conteúdos de cada curso do Programa Profuncionário (BRASIL, 2014b). Desta forma, os núcleos são articulados em módulos e estes, por sua vez, estão organizados em componentes curriculares.

No tocante ao Núcleo relativo à Formação Pedagógica fazem parte os seguintes temas: identidade do técnico em educação enquanto educador, gestor, profissional, cidadão e humano; educação, na qualidade de prática social, como formação, como ato político; cidadania, ao mesmo tempo como direito, conquista, projeto social e valor político; trabalho, na condição de elemento central na organização social como autoprodução humana; por fim, gestão democrática, entendida como gestão coletiva e participativa, em que se problematiza, reflete e investiga a realidade (BRASIL, 2014b).

Os componentes curriculares desse núcleo são desenvolvidos via estudo e da vivência da escola. Assim, esse núcleo apresenta como proposta:

Ampliar e movimentar a visão dos funcionários sobre a escola, tentando deslocar e
multiplicar os seus olhares, para que possam repensar e reorientar suas práticas e suas
relações nela e com ela, com a própria escola, com os demais segmentos que compõem
a comunidade escolar e, sobretudo, consigo mesmos, como pessoas e como categoria
profissional: educadores (BRASIL, 2014b, p. 84 , grifo do autor).

O IFMT atualmente está na quarta edição do Programa Profuncionário com a oferta dos cursos: Técnico em Alimentação Escolar, Técnico em Infraestrutura Escolar, Técnico em Multimeios Didáticos e Técnico em Secretaria Escolar. A matriz curricular dos cursos está distribuída em dois blocos. 
O primeiro bloco possui carga horária de 890 horas, sendo composto pelo núcleo da Formação Técnica Geral e pelo núcleo da Formação Pedagógica, cujos componentes curriculares são comuns às quatro habilitações, distribuídos da seguinte forma:

Quadro 2 - Componentes Curriculares da Formação Técnica Geral e Pedagógica

\begin{tabular}{|c|c|}
\hline Núcleo & Componentes Curriculares \\
\hline Formação Técnica Geral & $\begin{array}{l}\text { Orientações Gerais } \\
\text { Fundamentos e Práticas em EaD } \\
\text { Orientação da Prática Profissional } \\
\text { Informática Básica e Aplicada à Educação } \\
\text { Produção Textual na Educação Escolar } \\
\text { Direito Administrativo e do Trabalho }\end{array}$ \\
\hline Formação Pedagógica & $\begin{array}{l}\text { Funcionários de Escola: cidadãos, educadores, profissionais e gestores } \\
\text { Educadores e Educandos: tempos históricos } \\
\text { Homem, Pensamento e Cultura: abordagens filosóficas e antropológicas } \\
\text { Relações Interpessoais: abordagens psicológicas } \\
\text { Educação, Sociedade e Trabalho: abordagens sociológicas da educação } \\
\text { Gestão da Educação Escolar }\end{array}$ \\
\hline
\end{tabular}

Fonte: Projeto Pedagógico de Curso Técnico do Programa Profuncionário do IFMT ( 2017).

Os componentes curriculares do Núcleo da Formação Técnica Geral trazem temas entendidos como necessários para a profissionalização de todas as habilitações.

Os temas abordados pelos componentes curriculares do Núcleo da Formação Pedagógica destinam-se à apropriação e construção de conhecimentos científicos e filosóficos da educação, comum às quatro habilitações, necessários à formação e transformação do cursista em educador.

O segundo bloco possui carga horária de 610 horas, composto pelo núcleo da Formação Técnica Específica, nesse bloco cada habilitação possui componentes curriculares específicos, conforme quadros abaixo:

Quadro 3 - Componentes Curriculares Específicos do Curso Técnico em Alimentação Escolar

\begin{tabular}{|l|l|}
\hline \multicolumn{1}{|c|}{ Habilitação } & \multicolumn{1}{c|}{ Componentes Curriculares } \\
\hline & Alimentação e Nutrição no Brasil \\
& Alimentação Saudável e Sustentável \\
Curso Técnico em & Políticas de Alimentação Escolar \\
Alimentação Escolar & Produção e Industrialização de Alimentos \\
& Educação Alimentar e Nutricional nas Escolas \\
& Organização e Operação de Cozinhas Escolares \\
& Planejamento e Preparo de Refeições Saudáveis para Alimentação Escolar \\
\hline
\end{tabular}

Fonte: Projeto Pedagógico do Curso Técnico e Alimentação Escolar - Profuncionário/IFMT ( 2017). 
Quadro 4 - Componentes Curriculares Específicos do Curso Técnico em Infraestrutura Escolar

\begin{tabular}{|l|l|}
\hline \multicolumn{1}{|c|}{ Habilitação } & \multicolumn{1}{c|}{ Componentes Curriculares } \\
\hline & Teorias do Espaço Educativo \\
& Meio Ambiente, Sociedade, Higiene e Educação. \\
& Técnicas de Construção \\
Curso Técnico em & Equipamentos Hidráulicos e Sanitários \\
Infraestrutura Escolar & Equipamentos Elétricos e Eletrônicos \\
& Equipamentos e Materiais Didáticos \\
& Segurança na Sociedade e nas Escolas \\
\hline
\end{tabular}

Fonte: Projeto Pedagógico do Curso Técnico em Infraestrutura Escolar - Profuncionário/IFMT ( 2017).

Quadro 5 - Componentes Curriculares Específicos do Curso Técnico em Multimeios Didáticos

\begin{tabular}{|l|l|}
\hline \multicolumn{1}{|c|}{ Habilitação } & \multicolumn{1}{c|}{ Componentes Curriculares } \\
\hline & Teorias da Comunicação \\
& Audiovisuais \\
Curso Técnico em & Biblioteca Escolar \\
Multimeios Didáticos & Oficinas Culturais \\
& Laboratórios \\
& Informática Aplicada à Educação \\
& Informática Aplicada às Artes \\
\hline
\end{tabular}

Fonte: Projeto Pedagógico do Curso Técnico em Multimeios Didáticos - Profuncionário/IFMT ( 2017).

Quadro 6 - Componentes Curriculares Específicos do Curso Técnico em Secretaria Escolar

\begin{tabular}{|l|l|}
\hline \multicolumn{1}{|c|}{ Habilitação } & \multicolumn{1}{c|}{ Componentes Curriculares } \\
\hline & Trabalho Escolar e Teorias Administrativas \\
& Gestão Democrática nos Sistemas e na Escola \\
& Legislação Escolar \\
Curso Técnico em & Técnicas de Redação e Arquivo \\
Secretaria Escolar & Contabilidade na Escola \\
& Administração de Materiais \\
& Estatística Aplicada à Educação \\
\hline
\end{tabular}

Fonte: Projeto Pedagógico do Curso Técnico em Secretaria Escolar - Profuncionário/IFMT ( 2017).

Os temas abordados pelos componentes curriculares da Formação Técnica Específica buscam oferecer, ao funcionário estudante, conhecimentos técnicos e tecnológicos específicos de cada formação profissional, levando em consideração os princípios filosóficos, políticos e pedagógicos anteriormente descritos. De acordo com o documento orientador (BRASIL, 2014), existe um esforço para que os conteúdos desse núcleo sejam apropriados pelo funcionário estudante de forma reflexiva e crítica, de modo a contribuírem para a ressignificação da rotina e do saber fazer da vivência escolar.

Para o desenvolvimento da prática profissional, o cursista tem que desenvolver 300 horas de Prática Profissional Supervisionada (PPS) conforme consta no documento orientador do Programa Profuncionário. No PPC de cada curso ofertado, a carga horária da PPS está incluída carga horária de cada componente curricular.

A Prática Profissional Supervisionada (PPS) é o instante em que o funcionário estudante, a partir do que está sendo estudado, repensa seu fazer profissional, podendo, assim, 
transformar atividades rotineiras em práticas educativas intencionais (BRASIL, 2014b). Tais práticas estão sustentadas nos estudos realizados nos diferentes componentes curriculares dos outros núcleos e, aliadas às necessidades educativas da escola em que o funcionário da escola trabalha.

\section{Metodologia}

No que se refere ao aspecto metodológico a percepção de Moraes e Galiazzi (2013), é a de que a pesquisa qualitativa tem por objetivo desenvolver o aprofundamento da compreensão quanto aos fenômenos que se investiga, por meio de uma análise rigorosa e criteriosa. Para estes autores, a pesquisa qualitativa intenta interpretar, compreender e reconstruir conhecimentos existentes em relação ao tema investigado. Tal abordagem foi apropriada para o objetivo desta pesquisa, visto possibilitar o contato direto com os sujeitos pesquisados tornando possível compreender as repercussões do Programa Profuncionário nas suas trajetórias profissionais.

Objetivando perceber os principais conceitos e implicações do texto da lei na perspectiva do Programa Profuncionário, utilizamos a análise documental, que enquanto possibilidade no que se refere à pesquisa qualitativa consiste numa possibilidade a ser realizada a partir de documentos que não receberam tratamentos analíticos contemporâneos ou retrospectivos, considerados cientificamente autênticos, constituindo uma técnica importante na pesquisa qualitativa, seja complementando informações obtidas por outras técnicas, seja desvelando aspectos novos de um tema ou problema.

Trata-se de uma técnica decisiva para a pesquisa em ciências sociais e humanas, sendo indispensável porque a maior parte das fontes escritas ou, não, são quase sempre a base do trabalho de investigação.

Para Lüdke (1986: 38),

"[...] a análise documental pode se constituir numa técnica valiosa de abordagem de dados qualitativos, seja complementando as informações obtidas por outras técnicas, seja desvelando aspectos novos de um tema ou problema."

Dentre a diversidade relativa aos tipos de pesquisa da abordagem qualitativa, Triviños (1987) destaca que o Estudo de Caso é uma das mais relevantes. Trata-se de um tipo de pesquisa que pode ser utilizado, conforme afirma Yin (2010, p. 24), “[...] em muitas situações, para contribuir ao nosso conhecimento dos fenômenos individuais, grupais, organizacionais, sociais, políticos e relacionados". Ainda na visão de Yin (2010), se faz importante que o pesquisador preserve as características holísticas e significativas de eventos da vida real, quais sejam, “[...] 
ciclos individuais da vida, o comportamento dos pequenos grupos, os processos organizacionais e administrativos, a mudança de vizinhança, o desempenho escolar, as relações internacionais e a maturação das indústrias" (YIN, 2010, p. 24).

Entretanto, é interessante chamar a atenção para o fato de que dentre as características do Estudo de Caso, tem-se limitações. Assim, por estudar de forma aprofundada um programa, como é o caso do Profuncionário, os dados produzidos e sua análise ficam limitados a esse único caso. Dessa forma, não podem ser generalizados (MARCONI; LAKATOS, 2011). Porém, ainda que os dados desta investigação estejam limitados ao caso do Programa Profuncionário - IFMT, curso Técnico em Infraestrutura no polo Diamantino/MT, nossa compreensão é a de que os mesmos poderão colaborar com a reflexão e o aprimoramento da proposta do Programa em nível nacional, tendo em vista que sua oferta acontece em diferentes estados brasileiros.

\section{Resultados da Pesquisa}

Esta investigação foi realizada no polo de Diamantino, cidade localizada a $183 \mathrm{Km}^{2}$ da Capital Cuiabá, em Diamantino o IFMT possui um Centro Campus Avançado. Neste polo o tutor presencial atende 18 cursistas de Diamantino e cidades adjacentes, sendo que a maioria reside no município de Nova Maringá, distante de Diamantino cerca de $220 \mathrm{~km}$ sendo que o acesso é via estrada sem pavimentação.

O tutor cumpre carga horária semanal de 20 horas para atendimento presencial, no entanto, devido à distância, a maioria dos cursistas só comparece quando são realizados encontros específicos que acontecem mensalmente cuja locomoção é feita pelo transporte escolar.

De acordo com a organização pedagógica do curso, a matriz curricular relativa a ele, está dividida em dois blocos. O primeiro bloco contendo as disciplinas técnicas e pedagógicas que são comuns a todos os cursos e no segundo bloco as disciplinas específicas de cada curso. Dessa forma, ao final de cada bloco ocorre o Seminário Integrador, instante em que os cursistas apresentam os resultados da prática profissional supervisionada, desenvolvida no seu local de trabalho. A pesquisadora esteve presente durante a realização do $1^{\circ}$ Seminário Integrador onde teve a oportunidade de assistir as apresentações e constatar a riqueza com que cada cursista desenvolve seu trabalho. Algo que chamou a atenção foram os relatos de experiência de cada um, a sua vivência, sua história de vida e a transformação ocorrida nesse processo.

\subsection{OS SUJEITOS DA PESQUISA}


Os sujeitos envolvidos nesta investigação foram quatro cursistas do curso Técnico Infraestrutura Escolar do Programa Profuncionário - IFMT, polo Diamantino/MT. Cabe destacar que estes cursistas fazem parte da terceira edição (2017-2019) do Programa Profuncionário no estado do MT. Do total de dezoito estudantes que se matricularam no curso no ano de 2017, quinze se fizeram presentes no Seminário Integrador realizado no mês de novembro do ano de 2018.

Por meio de uma entrevista narrativa, a pesquisadora obteve relatos riquíssimos. Ao todo foram entrevistados quatro cursistas, sendo três homens e uma mulher. Os cursistas do sexo masculino atuam em duas escolas de Nova Maringá, sendo dois motoristas e um vigilante. A cursista atua como apoio administrativo.

A fim de apresentar o perfil dos cursistas em relação à idade, tempo de conclusão do Ensino Médio e tempo de trabalho em escola, foi elaborado o Quadro abaixo:

Quadro 7 - Dados do perfil dos Cursistas do curso Técnico em Infraestrutura

\begin{tabular}{|c|c|c|c|c|}
\hline Cursista & Idade & $\begin{array}{c}\text { Tempo de conclusão do } \\
\text { Ensino Médio }\end{array}$ & $\begin{array}{c}\text { Tempo de trabalho } \\
\text { em escola }\end{array}$ & Função \\
\hline C1 & 40 anos & 10 anos & 10 anos & Vigilante \\
\hline C2 & 53 anos & 08 anos & 05 anos & Apoio Administrativo \\
\hline C3 & 44 anos & 05 anos & 08 anos & Motorista \\
\hline C4 & 54 anos & 05 anos & 10 anos & Motorista \\
\hline
\end{tabular}

Fonte: Elaborado pela autora, 2019.

Além das informações contidas no Quadro 7, vale destacar as razões que levaram os cursistas a escolherem a educação como campo de trabalho. Dentre todos os entrevistados, apenas $\mathrm{C} 1$ afirmou que foi convidado para substituir uma pessoa que havia desistido da função. Todos os demais ingressaram na rede pública de ensino via concurso público.

Indagados quanto à motivação para o ingresso no Programa Profuncionário, assim os entrevistados afirmaram:

Um dos meus principais objetivos é melhorar meu desempenho enquanto funcionário público, obter mais informações sobre a escola onde trabalho enfim adquirir uma formação na função de funcionário. C1. Entrevista concedida em: 15/12/2018.

Também nesta perspectiva C3 afirma:

Os motivos que me levaram a ingressar nesse curso foram receber mais conhecimento na área da educação e também sentir que sou capaz de aprender e ir além do que eu poderia imaginar para mim. Entrevista concedida em: 15/12/2018.

C4 declara:

Os motivos que me levaram a ingressar no programa profuncionário foi que eu gosto de desafio e quero adquirir conhecimentos, pois aprender cada vez mais me 
entusiasma, e assim executar melhor meu trabalho, pretendo me capacitar para ajudar aos alunos que tem dificuldade ou problemas do dia a dia, com o que eu aprendo neste curso, e para melhorar meu salário também. Entrevista concedida em: 15/12/2018.

Diferente de C1, C2 menciona ingressar no Programa "Para me aperfeiçoar na minha área de trabalho".

A facilidade foi o apoio de minha família, colegas e amigos, já a dificuldade por esta longe do polo, pois a distância complica um pouco, o Programa do Profuncionário está contribuindo muito para meus conhecimentos e facilita interagir com os alunos e colegas de trabalho. Entrevista concedida em: 15/12/2018.

No que tange as facilidades e dificuldades encontradas no desenvolvimento do curso, os atores sociais pertencentes ao programa destacam:

Uma das maiores dificuldades foi: o pouco tempo para estudar os fascículos, a distância do polo, o sistema que dificulta o acesso às informações da plataforma. $\mathrm{C} 1$. Entrevista concedida em: 15/12/2018.

A percepção de $\mathrm{C} 2$ em relação às dificuldades e facilidades é evidenciada em diferentes categorias, a saber:

Pessoais - tive apoio da minha família e colegas de trabalho.

Profissionais - tivemos acesso à escola para nos reunirmos e desenvolvermos nossos projetos.

Pedagógicos - recebemos os materiais pedagógicos para estudarmos, não tivemos muitos encontros por falta de um tutor presencial.

Tenho muita dificuldade no ambiente virtual, pois não tenho muito conhecimento de informática. Entrevista concedida em: 15/12/2018.

C3 destaca que:

A facilidade foi o apoio de minha família, colegas e amigos, já a dificuldade por esta longe do pólo, pois a distância complica um pouco, o Programa do Profuncionário está contribuindo muito para meus conhecimentos e facilita interagir com os alunos e colegas de trabalho. Entrevista concedida em: 15/12/2018.

Na mesma direção dos demais, C4 declara que:

Durante o curso as facilidades foram que eu tenho apoio da família, colegas, tutores e chefe, para me ajudarem naquilo que eu precisar e não me deixar desanimar, sempre me encoraja para nunca desistir. Portanto tive e tenho muitas dificuldades, pois tenho pouco tempo disponível e preciso fazer de tudo para conciliar os estudos com o trabalho, também tenho dificuldade em manusear o computador, o ambiente de informática me dificulta muito, mas com ajuda estou aprendendo.

Compreender a importância do trabalho em de equipe, envolvimento dos pais, escola, enriquecimento do conhecimento enquanto pessoa. C1. Entrevista concedida em: $15 / 12 / 2018$.

Ao ser questionado quanto à forma pela qual desenvolviam o trabalho na escola antes da participação no programa, C1 afirma que "sentia-se inseguro em argumentar sobre as ordens atribuídas, certa ou não os cumpria, tinha maior conhecimentos sobre meus deveres e pouco conhecia meus direitos". E argumenta que a realização do curso permite que ela se "sinta mais 
autônoma na hora de expor minhas opiniões, questionar sobre assuntos referentes ao trabalho escolar; hoje tenho maior conhecimento sobre meus deveres e meus direitos".

$\mathrm{A}$ percepção de $\mathrm{C} 2$ quanto às contribuições do Programa Profuncionário no desenvolvimento de sua identidade enquanto profissional da educação é a de que "o curso é muito bom, pois faz entender a importância do nosso trabalho para o desenvolvimento da escola, que podemos contribuir na educação dos alunos". Destaca que antes da participação no curso "sempre exerceu a função com dedicação e empenho, mas agora está mais ciente da importância do trabalho que desenvolve".

Tal percepção é corroborada por C3 ao afirmar que "antes de ter começado a fazer esse curso era um pouco reprimido em relação ao ambiente de trabalho e dificuldade em interagir com todos os educadores, houve uma grande mudança e ainda está ocorrendo, pois, cada módulo estudado eu aprendo muito mais".

C4 argumenta que "as contribuições do Programa Profuncionário no desenvolvimento da sua pessoa foram muitas, porque todos os componentes curriculares que estudou foram bons e proveitosos, pois trouxeram conhecimentos para o desenvolvimento do profissionalismo". Assim, “os exercícios da função sempre são executados da melhor maneira possível, pois tem conseguido colaborar e dar apoio na manutenção do veículo em que trabalha". Enfatiza que "não ocorreram mudanças no trabalho, mais sim, na forma com que transporta as pessoas", utilizando o viés educativo.

Em relação à proposta pedagógica, os cursistas evidenciam que tudo veio a somar com a formação pessoal e profissional, mais acreditam que alguns pontos deveriam passar por ajustes, não por ter deixado a desejar, mas para ficarem ainda melhor, pois melhorias nunca é demais só vem a contribuir. Afirmam que tem aprendido bastante, conhecendo pessoas de outros municípios, entendendo que nada vem de graça para as pessoas. "Se queremos alcançar algo temos de correr atrás, pois nada cai do céu". C1

C2 afirma que "busca desenvolver seu trabalho com muita dedicação, pois ocorreram algumas mudanças no trabalho, como por exemplo, a valorização da função, pois agora existe a consciência de que são educadores". Tal perspectiva vem ao encontro do que defende Stering (2008), que afirma:

A consciência nasce no/do diálogo, num complexo relacional de subjetividades socialmente configuradas, onde apreende preferências e experiências, o peso pessoal da liberdade e da decisão; esta, entendida no sentido de que todo ato de liberdade ou de escolha implica uma cisão, um corte, uma restrição que se realiza numa liberdade situada. Com os outros-eus vai o sujeito estabelecendo contratos, consensos, parâmetros, razões, futuros, riscos, sob a ameaça constante de vitória ou fracasso, na 
luta por transformar o espaço em que vive mediante a prática de uma ansiada cultura de paz. (STERING, 2008, p.26).

Destaca C2 que "não sabe bem o que dizer sobre a proposta pedagógica, mas esse curso tem ajudado a expandir os conhecimentos, buscando melhorar a cada dia". Contudo, destaca que "tem muito a aprender e vai continuar buscando mais conhecimento".

C3 afirma que "o curso é muito importante para o seu currículo profissional, e também muito das coisas que aprende coloca em prática em seu trabalho, sendo que a metodologia usada pelos tutores está sendo muito boa". Tal percepção é corroborada por C4 que menciona que "a metodologia utilizada está alcançando objetivo de ensinar, pois com ele está aprendendo cada vez mais". Destaca que a modalidade EAD, proporcionou a ele a oportunidade de fazer o primeiro curso técnico, onde se este fosse presencial não teria como participar por causa do trabalho e da distância de onde mora.

É perceptível que as metodologias utilizadas para o desenvolvimento da prática pedagógica no Programa Profuncionário, apresentam conteúdos e possibilidades de avaliação processuais permeadas por uma base política estimuladora de transformações sociais e orientadas por anseios humanos de liberdade, justiça e igualdade.

\section{ANÁliSE de DADOS}

Ao analisarmos os reflexos da formação continuada em serviço, podemos afirmar que o Programa Profuncionário tem cumprido o seu papel social no processo formativo dos servidores não docentes pertencentes à educação e na mesma perspectiva, possibilitando o exercício pleno da cidadania, que conforme Carvalho (2002) consiste no usufruto dos direitos civis, políticos e sociais Assim, por ser a educação, um direito social, o Programa Profuncionário tem transformado servidores em educadores, conforme afirma $\mathrm{C} 3$;

Antes eu era somente um motorista que buscava e levava os alunos pra escola. Fazia isso somente como motorista que dirigia o ônibus. Hoje eu não sou um simples motorista. Hoje eu sou um Profissional da Educação que transporto os alunos, mas converso com eles, oriento. Sinto-me às vezes como um pai e estou sempre disposto a ajudar cada um. Não sou um motorista robô. Sou um motorista humano que no meu trabalho contribuo com a educação desses alunos.

Embora o Programa Profuncionário cumpra com o seu papel social, nem tudo são flores. O processo educativo é perpassado por desafios que requerem dia a dia a superação, a fim de garantir a aprendizagem significativa e o processo de transformação da dimensão profissional.

Conforme $\mathrm{C} 4$,

O ambiente virtual de aprendizagem para mim é difícil porque tenho pouco conhecimento de informática. A tutoria presencial está sendo ótima, pois me orienta em tudo que preciso, os professores formadores estão sempre me orientando e 
avisando sempre do tempo de cada matéria para não perder a data das atividades e dia de postar os trabalhos.

Fica evidente que a prática pedagógica desenvolvida no Programa profuncionário não é perfeita. É perpassada por ambiguidades, que em seu sentido etimológico significa: "[...] que se pode tomar em mais de um sentido" (Aurélio, 2001), ou "o que apresenta duas naturezas diferentes" (Larousse, 2001). Ou seja, a ambiguidade constitui uma das características que permeiam as ações do Programa em tela. Importante se faz destacar, em consonância com o pensamento de Chauí (1987), que a ambiguidade não é falha, defeito ou carência de um sentido que seria rigoroso se fosse unívoco. Ambiguidade, na visão de Chauí, é a forma de existência dos objetos da percepção e da cultura, percepção e cultura sendo, elas também ambíguas constituídas não de elementos ou de partes separáveis, mas de dimensões simultâneas.

\section{CONSIDERAÇÕES FINAIS}

Após a contextualização e recolha de dados via entrevistas semiestruturadas o objetivo deste artigo buscou analisar por meio da prática pedagógica desenvolvida no Programa em tela, os reflexos da formação continuada em serviço por meio do Programa Profuncionário, junto aos cursistas do Polo Cefapro de Diamantino, residentes no município de Nova Maringá - MT, por meio da percepção dos cursistas. A pesquisa evidenciou que, mesmo com muitas dificuldades, têm buscado meios para ampliar o uso das Tecnologias de Informação e do Conhecimento, em busca de melhores resultados do trabalho junto ao processo formativo, os cursistas se esforçam para desenvolver com responsabilidade e determinação os pratique, em busca de melhoria da qualidade da função que lhe é atribuída e da busca por satisfação pessoal e profissional, bem como pelo desenvolvimento de uma prática educativa significativa na instituição de ensino em que estão inseridos.

Neste contexto, podemos assegurar que as ações desenvolvidas pelo Programa Profuncionário fornecem subsídios para que os atores tomem consciência de que são sujeitos da sua própria história, e são por isso, por ela, responsáveis. Da mesma forma, a educação é via de mão dupla, pois estabelece uma relação horizontal entre os participantes do processo educativo, rompendo, dessa forma, com a visão tradicional em que apenas um ensina.

Podemos afirmar que as ações desenvolvidas mediante Programa Profuncionário potencializam a profissionalização de homens e mulheres, que deixam a condição de servidores, para atuarem como educadores no chão da escola, mesmo em uma atuação diferente da docente, de forma ética e cidadã. Sabemos que o programa possui lacunas, mas nada que não permita o desenvolvimento de práticas educativas que não paralisam a ação coletiva, a luta pela inclusão, 
pela construção de espaços mais igualitários de reconhecimento e de garantia de direitos via processos educativos.

Mesmo diante da existência de dispositivos legais, que tratam das políticas públicas de formação dos profissionais da educação, recomendarem a necessidade de aperfeiçoamento e qualificação de todos os trabalhadores da educação, a concretização parece estar distante. Os cursistas, sujeitos desta pesquisa, acessaram e concluíram um processo formativo por meio do Programa Profuncionário, no entanto, cabe problematizar sobre a formação dos demais funcionários da escola, uma vez que, mesmo com o advento da Sala do Educador, que promove as formações pedagógicas com todos os atores sociais pertencentes à unidade escolar, o foco em geral, ainda são os professores.

\section{REFERÊNCIAS}

ARRIAL, Luciane Roso de. Solidariedade como fundamento ético para a formação do Educador Ambiental: estudo de caso no Curso Técnico em Infraestrutura Escolar do Programa de Educação a distância do Profuncionário - IFSul. 2016. 231 f. Tese (Doutorado em Educação Ambiental) - Universidade Federal do Rio Grande - FURG, Rio Grande, 01 ago. 2016. Disponível em:

$<$ https://sucupira.capes.gov.br/sucupira/public/consultas/coleta/trabalhoConclusao/viewTrabal hoConclusao.jsf?popup=true\&id trabalho=3004486> . Acesso em: 10 jan. 2019.

BESSA, Dante D. Profuncionário: curso de formação para os funcionários da educação. Revista Retratos da Escola, Brasília, v. 3, n. 5, p. 485-487, jul./dez. 2009. Disponível em: $<$ http://www.esforce.org.br>. Acesso em: 10 nov. 2018.

BESSA, Dante D. A carreira dos funcionários da educação: a concepção de formação do Profuncionário. Revista Retratos da Escola, Brasília, v. 10, n. 18, p. 201-214, jan./jun. 2016. Disponível em: 〈http://www.esforce.org.br〉. Acesso em: 02 nov. 2018.

BRASIL. Lei no 9.394, de 20 de dezembro de 1996. Estabelece as diretrizes e bases da educação nacional. Disponível em: 〈http://www.planalto.gov.br/ccivil_03/LEIS /19394.htm〉. Acesso em: 04 jan. 2019.

BRASIL. Resolução no 6, de 20 de setembro de 2012. Define Diretrizes Curriculares Nacionais para a Educação Profissional Técnica de Nível Médio. Disponível em: <http://mobile.cnte.org.br:8080/legislacao-externo/rest/lei/51/pdf $>$. Acesso em: 09 nov. 2018.

BRASIL. Ministério da Educação. Secretaria de Educação Profissional e Tecnológica. Orientações Gerais. 4. ed. atualizada e revisada. Cuiabá: Universidade Federal de Mato Grosso / Rede e-Tec. Brasil, 2014b.

CHAUÍ, Marilena. Conformismo e resistência: aspectos da cultura popular no Brasil. 2.ed. São Paulo: Brasiliense, 1987. 
CARVAlHO, José Murilo de. Cidadania no Brasil. O longo Caminho. 3. ed. Rio de Janeiro: Civilização Brasileira, 2002.

CHARLOT, Bernard. Da relação com o saber: elementos para uma teoria. Tradução Bruno Magne. Porto Alegre: Artes Médicas Sul, 2000.

DICIONÁRIO LAROUSSE ESCOLAR DA LÍNGUA PORTUGUESA. São Paulo: Larousse do Brasil, 2001.

FERREIRA, Aurélio B. Holanda. Mini Aurélio o Dicionário da Língua Portuguesa Revista e Ampliada. Curitiba: Editora Positivo, 2001.

FREIRE, Paulo. Pedagogia da Autonomia: saberes necessários à prática educativa. 11 . ed. São Paulo: Paz e Terra, 1996.

GIL, Antonio C. Didática do Ensino Superior. São Paulo: Atlas, 2015.

LÜDKE, M., ANDRÉ, M. E. C. A. Pesquisa em educação: abordagens qualitativas. São Paulo: EPU, 1986.

MARCONI, Marina de Andrade; LAKATOS, Eva M. Metodologia Científica. 6. ed. São Paulo: Atlas, 2011.

MATO GROSSO. IFMT/ CONSUP. Resolução No 041 de 27 de julho de 2017. Aprova o Projeto Pedagógico do Curso Técnico em Alimentação Escolar Subsequente ao Nível Médio/Profuncionário/Pronatec do IFMT/Proen/DeaD.

MATO GROSSO. IFMT/ CONSUP. Resolução No 042 de 27 de julho de 2017. Aprova o Projeto Pedagógico do Curso Técnico em Infraestrutura Escolar Subsequente ao Nível Médio/Profuncionário/Pronatec do IFMT/Proen/DeaD.

MATO GROSSO. IFMT/ CONSUP. Resolução No 043 de 27 de julho de 2017. Aprova o Projeto Pedagógico do Curso Técnico em Secretara Escolar Subsequente ao Nível Médio/Profuncionário/Pronatec do IFMT/Proen/DeaD.

MATO GROSSO. IFMT/ CONSUP. Resolução No 044 de 27 de julho de 2017. Aprova o Projeto Pedagógico do Curso Técnico em Multimeios Didáticos Subsequente ao Nível Médio/Profuncionário/Pronatec do IFMT/Proen/DeaD.

MONLEVADE, João Antônio C. Funcionários de escolas: cidadãos, educadores, profissionais e gestores. 3. ed. Brasília, DF: Universidade de Brasília/Centro de Educação a Distância. 2009.

MORAES, Roque; GALIAZZI, Maria do C. Análise Textual Discursiva. 2. ed. Ijuí: Unijuí, 2013.

STERING, Silvia Maria dos Santos. Ritmos e tons das ações instituintes da educação popular: um olhar fenomenológico da Orquestra de Flautas Meninos do Pantanal. Dissertação de Mestrado. Universidade Federal de Mato Grosso. 2008. 
TRIVIÑOS, Augusto. Introdução à pesquisa em ciências sociais: a pesquisa qualitativa em educação. São Paulo: Atlas, 1987.

YIN, Robert K. Estudo de Caso: planejamento e métodos. Tradução de Daniel Grassi 4. ed. Porto Alegre: Bookmann, 2010.

ZABALA, Antoni; ARNAU, Laia. Como aprender e ensinar competências. Porto Alegre: Artmed, 2010.

Recebido em: 05 de abril de 2019.

Aprovado em: 17 de junho de 2019. 